\title{
Applying a newswriting research approach to translation
}

\author{
Maureen Ehrensberger-Dow and Daniel Perrin \\ Zurich University of Applied Sciences, Switzerland
}

\begin{abstract}
Translation is a situated activity that involves more than simply producing target texts from source texts. In order to understand what translators actually do when they translate, their psycho-biographies as well as the social setting of the workplace and the contextual resources must be considered. In this paper, we outline how a mixed-method approach originally developed to study the newswriting processes of journalists at their workplaces can be applied in translation process research. We argue that progression analysis, which combines keystroke logging, screen recordings, eye-tracking, and cue-based retrospective verbalization, can be profitably used along with version analysis to gain insights into cognitive aspects of the translation process.
\end{abstract}

Keywords: translation process, newswriting research, progression analysis, eyetracking, version analysis

\section{Introduction}

From an almost exclusive focus on products, translation studies has moved towards examining processes (including cognitive aspects) and the effects of those processes on the quality of products (cf. Lee-Jahnke 2005). The latter are the result of the interaction between societal expectations of what translations should be and translators' emergent practices and translation competence that allow them to produce acceptable translations in a given setting or situation within temporal and economic constraints (cf. Archer 2003).

In this paper, we show how research with another group of language professionals, namely journalists, can be applied to investigate the situated activity of translation. Since we are interested in releasing expert knowledge by gaining an understanding of what language professionals actually do, we have chosen a rather complex method mix based on an approach called progression analysis. A case 
study and comparison data from the corpus of a longitudinal project ${ }^{1}$ are presented to illustrate the applicability of this approach to translation.

\section{The relevance of newswriting research for translation studies}

Writing research conceptualizes writing as the production of texts, as cognitive problem solving, and as the collaborative practice of social interaction and meaning making (Juzwik et al. 2006; Rijlaarsdam et al. 1996). Newswriting research sees text production as a reproductive process in which professional journalists transform source texts into target texts (Jacobs 2011; Perrin 2012; Van Hout et al. 2011). This happens at collaborative workplaces, in processes of goal setting, planning, formulating, and revising. Reading phases are integrated in the process: journalists read source texts and their emerging own text before, while, and after writing (Perrin, in press). The parallels to the activities of translators during the translation process would seem obvious.

The present state of writing research results from two paradigm shifts, which have their correlates in translation studies. In a first paradigm shift, the focus of interest moved from the product to the process. A second paradigm shift took research from the lab to the field, as researchers moved from testing subjects with experimental tasks to ethnographic approaches of investigating communities of practice. Later, ethnography was complemented by recordings of writing activities, such as keystroke logging. The research reviewed below reflects the influence of these paradigm shifts on methods used in empirical writing research and translation process research.

\subsection{Parallels between writing and translation process research methods}

Not only are most news texts and translations now produced on computers, many are transmitted to their audiences solely in electronic form. Recent writing and translation process research has been quick to exploit the possibilities offered by the technological developments that have dramatically altered text production and translation processes. At each phase of their production, texts and translations can be reconstructed and analyzed with respect to various characteristics by using non-invasive techniques such as keystroke logging (e.g., Van Waes and Leijten 2006 in writing research and Jakobsen 2006 in translation research). Logfiles are useful for investigating pauses and micro-changes at different stages of the writing or translation process, although they provide no information about what a writer or translator might be doing when they are not entering text into the computer or using the mouse. However, other methods can overcome this limitation to provide richer information about the 
process. For example, screen capture software records all the changes that take place on the computer screen during a writing or translation process. Eye tracking, which monitors eye movements and gaze intensity, can provide information about the focus of attention, such as when a writer or translator switches screens to refer to a source of information or to check for a word in an online thesaurus.

From a product perspective, version analysis is the method of collecting and analyzing data in order to reconstruct the changes that a text undergoes during its production or to compare linguistic differences in texts produced by various individuals. The basis for comparing versions is text analysis. Version analysis traces linguistic products and elaborates on the changes in text features from version to version throughout intertextual chains (cf. Perrin and Ehrensberger-Dow 2008, 286-287 for writing and Englund Dimitrova 2005, 143-144 for translation processes). However, version analysis alone fails to provide any information about whether the journalists or translators were conscious of their actions during text production and revision. To generate such knowledge, additional methods such as self-report or interviews are required.

Concurrent and retrospective verbalizations are forms of self-report that have been exploited in both writing and translation research (cf. Levy et al. 1996 and Jääskeläinen 2011, respectively). Although concurrent reports are widely used in psychology and language studies, they have been criticized for affecting the process that is being commented upon. Cue-based retrospection, performed immediately after task execution, has been identified as an ecologically valid alternative to concurrent verbalization (cf. Hansen 2006; Perrin 2003; 2006). An important advantage of this technique is that different modes of expression (writing and talking) do not have to be used simultaneously; the talking has no impact on the writing or translation process because it happens afterwards.

\subsection{Methodological considerations}

Within and across disciplines, the question as to which research method suits which research question is dealt with by methodology, the scientific cross-sectional discipline that deals with the relationship between the object of study, research question, methods, and the expected results in scientific research. Some of the methodological dichotomies include: quantitative vs. qualitative; statistical representation vs. case studies; laboratory research vs. field studies; structured questionnaires vs. observation; and single vs. multi-method approach. Whereas methodologically rigorous positions tend to concentrate on a single theory and method, pragmatic positions prefer to combine them in order to gain multi-perspective insights (Tashakkori and Teddlie 2003). Such a combination of methods is exemplified by progression analysis. 


\section{Progression analysis in newswriting research}

Progression analysis was originally developed to investigate newswriting (Perrin $2003 ; 2006)$. It is a multi-method approach of collecting and analyzing data in natural workplace settings at different levels, in order to reconstruct text production processes as a cognitively controlled and socially anchored activity. Progression analysis operates on three levels: situation, performance, and conceptualization.

1. On a situation level, progression analysis determines through interviews and observations what the writing situation is and what experience journalists draw on to guide their actions. Important factors include the writing task, professional socialization, and economic, institutional, and technological influences on the work situation. Data on the self-perception of the journalists under investigation are obtained in semi-standardized interviews about their psychobiography, primarily in terms of their writing and professional experience, and their workplace. In addition, participatory and video observations are made of their situated activity at the workplace, including various kinds of collaboration.

2. On a level of practice or performance, directly observable actions such as revisions in a growing text are logged and analyzed. During newswriting, keystroke logging and screen recording programs, which run unobtrusively in the background behind the text editors that the journalists usually use, record every keystroke and writing movement in the emerging text. The recordings can follow the writing process over several workstations and do not influence the performance of the editing system or the journalist.

3. On the level of socio-cognitive conceptualization or reconstruction, progression analysis draws on verbal data to infer the mental structures that might have guided the writing activities observed on the second level. After writing is completed, journalists view a playback of their process and watch how their texts came into being. While doing so, they continuously comment on what they did while writing and why they did it. An audio recording is made of these cue-based retrospective verbal protocols (RVPs). It is assumed that this third level of progression analysis reveals considerations that a journalist could have made in principle, if not the sum of all and only the considerations that the journalist actually made. The cue-based RVP is transcribed and then encoded as the journalist's verbalization of aspects of his or her language awareness, writing strategies, and conscious writing practices.

The data from these three levels complement each other to provide a multi-perspective, vivid picture of newswriting. Visualizations of the data help with the detection of problematic points in the emerging texts, and the computer logs provide 
detailed information about what happens during the process at those points. Finally, the cue-based RVPs provide information about the journalists' awareness of what they are doing and why.

In sum, progression analysis allows researchers to consider all the revisions to the text as well as all of the electronic resources accessed during the production process; to trace the development of the emerging media item; and finally to reconstruct collaboration at media workplaces from different perspectives. The focus of progression analysis is the socially embedded cognitive and manifest processes of writing by individuals: their situated activity in context. The next section explains how progression analysis can be and has been applied in the context of translation, in order to obtain a deeper understanding of the decisions that translators make during the translation process.

\section{Tracing translation processes with progression analysis}

In a longitudinal study of translation processes ${ }^{2}$, we have applied progression analysis at all three levels: the situation surrounding the translation activity (4.1); the translation movements and practices that the translators engage in (4.2); and the translation strategies that can be inferred from the translators' comments about their translation processes (4.3). In addition, we have used version analysis to investigate the emergence of individual target texts and to compare translations of the same source text produced by different translators under controlled conditions (4.4). The detailed analysis of the case study presented below exemplifies how progression analysis can be used in translation process research.

\subsection{First level of progression analysis: the translation situation}

The translation situation includes the linguistic, educational, and professional background information of the translators as well as the setting and the task demands. The woman (ET0413) whose process is presented below was one of five paid volunteers who had recently completed a four-year undergraduate translation degree program and was enrolled in the first semester of a post-graduate interpreting program. Her first language (L1) was German, her strongest foreign languages (L2) were English and Italian, and her less active language was French. She had also taken part in data collection for the research project in her undergraduate program, so was accustomed to having her translation processes monitored. She was told that her translation process was being recorded in order to test the new eye-tracking equipment. ${ }^{3}$ 
The setting for the translation process was the institute's usability lab; the computer that the participant was working at had the same MS Office environment that she was familiar with from other institute computer workstations as well as access to the internet, institute online dictionaries, and other university library resources. After a brief session in the usability lab to become familiar with the setting and the eye-tracking equipment (Tobii T60), she took part in three recording sessions spread over a period of two months: the process considered here was done in the first session.

The participant was given as much time as she needed to translate a German journalistic source text of about 115 words into English (see Appendix A). The translation brief was provided, as was the link to the article in the online publication that it originally appeared in. After about 20 minutes, she indicated that she was finished. Immediately afterwards, the screen recording of her translation process was retrieved on a laptop computer in a room adjacent to the usability lab, and she commented on what she had done while she viewed the recording of her process replayed in real time. A research assistant was present during the verbalization but sat where the computer screen could not be seen easily, not only to increase the ecological validity of using verbalization as a method but also to prompt the participant to continue talking whenever necessary. The participant was asked to talk about what she was watching but was not asked to provide explanations of her actions or given any indication of what type of comments might be of particular interest to the researchers.

\subsection{Second level of progression analysis: translation activities and practices}

Keystroke logging and screen capture software record the development of the emerging translation, all of the revisions to it as well as the search terms and electronic resources that were accessed during the translation process. In the process considered here, the translation of the 5th sentence of the source text (ST) is examined in detail:

Laut dem EU-Schnellwarnsystem RAPEX erwiesen sich 2006 erstmals Spielzeuge als gefährlicher als Elektrogeräte. ${ }^{4}$

In the final version of ET0413's target text (TT), the corresponding sentence appeared as:

According to the EU rapid alert system RAPEX, toys had proven more dangerous than electronic devices for the first time in 2006.

It took the translator just over two minutes to produce the first complete version of the sentence, measured from when she typed the capital letter at the start of the 
sentence until she typed the full stop at the end. During that time, she interrupted the flow of her translation twice to do research and numerous times to make revisions, such as deleting or inserting letters and/or words. Each step resulted in a new version of the sentence (see Appendix B). After she finished her first draft, as indicated by typing the final punctuation of the last sentence of the target text, she worked through her translation in a short revision phase, making four more revisions to the 5 th sentence of her TT.

Although the first two revisions in the introductory phrase of the TT sentence seemed to be related to typing slips (typos), the following revisions, especially those related to two time adverbials, seem to reflect difficulties related to translation direction. The multi-method approach of progression analysis allows us to reconstruct the translation process, as presented below, with data elicited with each method allowing insights into the various steps of the overall process.

\subsubsection{Computer logging}

The keystroke logging software InputLog, developed by the writing researchers Van Waes and Leijten (2006), was used to record the timing of keystrokes, mouse movements, clicks, wheel movements, references to URLs, and pauses during the target-text production process. The software is compatible with many user interfaces and has no restrictions with respect to window size or layout. With the log data, it is possible to reconstruct the phases of the translation process and to determine the time required to research and produce each sentence of the target text (Table 1). Excluding the time spent on research, the translator took longer to complete the 5th sentence (i.e., time between writing the first lettter and the final punctuation) than any other sentence of the target text, although it was not the longest.

A challenge in carrying out newswriting or translation research in workplace settings is to ensure that the logging software records not only the timing of keystrokes, mouse movements, and shifts between windows but can also trace

Table 1. Temporal information about ET0413's translation process from the logfile

\begin{tabular}{|c|c|c|c|c|c|}
\hline Phase & Target text & $\begin{array}{c}\text { Words } \\
\text { (ST) }\end{array}$ & $\begin{array}{l}\text { Overall duration } \\
(\mathrm{msec})\end{array}$ & $\begin{array}{l}\text { Research } \\
(\mathrm{msec})\end{array}$ & $\begin{array}{l}\text { TT production } \\
(\mathrm{msec})\end{array}$ \\
\hline Orientation & & & 101203 & 31281 & 0 \\
\hline \multirow{9}{*}{  } & Title & 4 & 5875 & 0 & 5875 \\
\hline & 1st sentence & 16 & 74047 & 22204 & 51843 \\
\hline & 2nd sentence & 25 & 201672 & 91063 & 110609 \\
\hline & 3rd sentence & 10 & 115953 & 57343 & 58610 \\
\hline & 4th sentence & 15 & 153859 & 52281 & 101578 \\
\hline & 5th sentence & 13 & 133875 & 15407 & 118468 \\
\hline & 6th sentence & 14 & 70593 & 21828 & 48765 \\
\hline & 7th sentence & 16 & 114797 & 48186 & 66611 \\
\hline & URL link & 1 & 7046 & 0 & 7046 \\
\hline Revision & & & 149734 & 0 & 149734 \\
\hline
\end{tabular}


changes to an emerging translation that result from the use of tool functionalities such as cut, paste, auto-correct, and match (i.e., from translation memory software). In the absence of customized logging software that automatically records that information, screen recordings can be made with software such as Camtasia Studio and those types of actions can be transcribed manually. The function of mouse movements and clicks relative to the emerging text usually becomes apparent through an examination of the screen recordings. In addition, detailed information about electronic resource and tool use can be obtained from the screen recordings. Analyzing these recordings takes far more time than an automatic analysis of logfiles but adds relevant data about the process.

\subsubsection{S-notation}

Although micro changes during text production can be traced in the output of logging software, the degree of detail can make it extremely difficult to gain an overview of the process. The presentation of individual revision steps (such as those in Appendix B) may be useful for illustrative purposes but is extremely time- and space-consuming to produce. To address this problem in writing research, a system known as S-notation was developed to depict the steps in logfiles in order to simplify the detail analysis of a text production process (Kollberg 1998; Kollberg

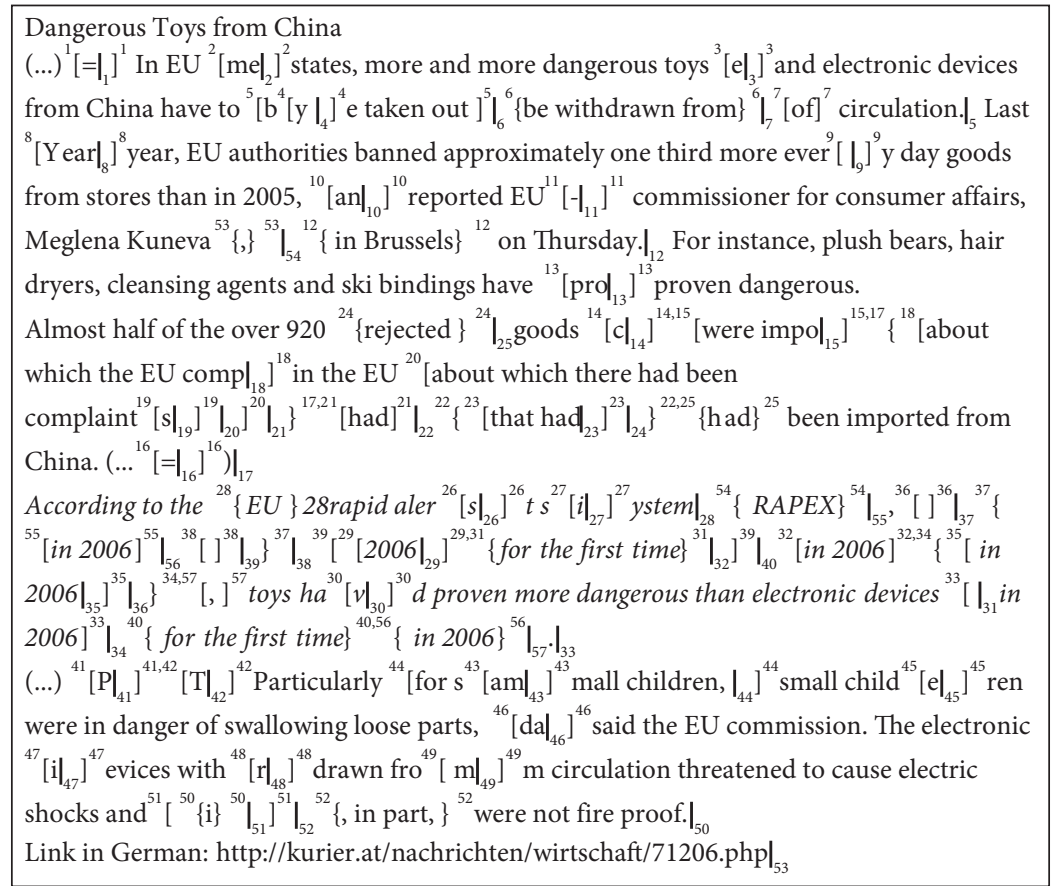

Figure 1. S-notation of ET0413's translation process (5th sentence indicated with italics) 
and Severinson-Eklundh 2001). Whenever a writer or translator interrupts the flow of text production to delete something in the text (e.g., with a backspace, delete, or cut command) or to insert something at another place, S-notation indicates this with a numbered break symbol in the text. Deleted text is indicated in square brackets, and insertions in curly braces. The order of any given writing interruption is provided by a subscript to the right of the break symbol $\left.\right|_{n}$ and by matching superscripts on either side of the brackets ${ }^{n}[]^{\mathrm{n}}$ or braces ${ }^{\mathrm{n}}\{\}^{\mathrm{n}}$.

Figure 1 shows the revisions in ET0413's translation process compressed with $S$-notation. The almost linear increase in the numbers over the first four sentences of the target text and at the beginning of the 5th sentence indicates a relatively smooth translation process. In the second part of the 5th sentence, the numbers are out of sequence, although they again increase linearly in the last two sentences of the TT. One way to visualize this progression of TT production is explained in the next section.

\subsubsection{Progression graphs}

The broader pattern of the revisions that are captured in the logfiles and compressed with S-notation can be traced in a graph that reflects the development of the translation over time. Perrin (2003) developed progression graphs such as the one in Figure 2 to provide an overview of the course of writing. The order of the revisions in the writing process is shown on the horizontal axis, and the position of the revisions in the final target text is on the vertical axis. If a writer or translator completed a text by only moving forward, deleting all the typos immediately and

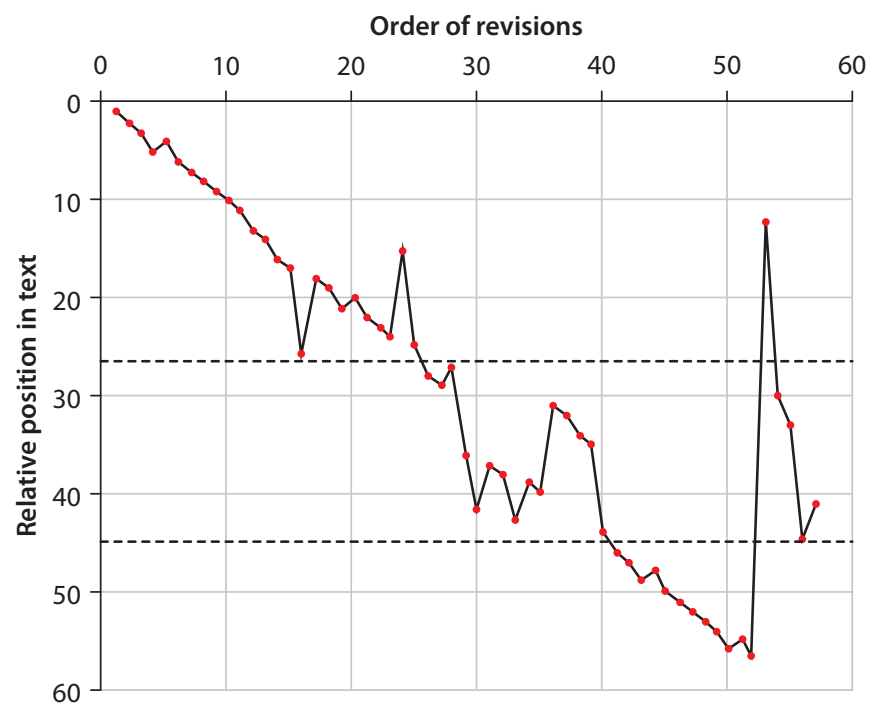

Figure 2. Progression graph of ET0413's translation process 
never jumping back to previous parts of the text, the graph would be a straight line from the upper left corner to the lower right. In contrast to this idealized scenario, writers and translators often delete words, move parts of their emerging text to different locations, and insert new text in previously written sections. All of these revisions appear on the progression graph as dots that are linked to form a more or less jagged line, which reflects the course of the text production.

The smoothness in translating the first part of the ST is apparent in the progression graph of ET0413's process (Figure 2). The revisions in the 5th sentence are delimited by the dotted lines: the uneven line in this section reflects how often the translator returned to an earlier part of the sentence to delete or insert text. The beginning of the revision phase of the translation process is obvious, since the line has a generally negative slope until the 53rd revision, which indicates a return to the beginning of the text. All of the subsequent revisions were made to the 5 th sentence.

\subsubsection{Eye-tracking}

Progression analysis has recently been extended to include eye-tracking data when feasible. Such data complement the description of the writing or translation process by providing information about the focus of attention on the screen. This can be especially useful to understand the function of pauses in text production or in considerations of the role of reading in the writing or translation process. For example, the translator read the brief and the whole ST before starting her translation phase. She reread the introductory phrase of the 5 th sentence before and during

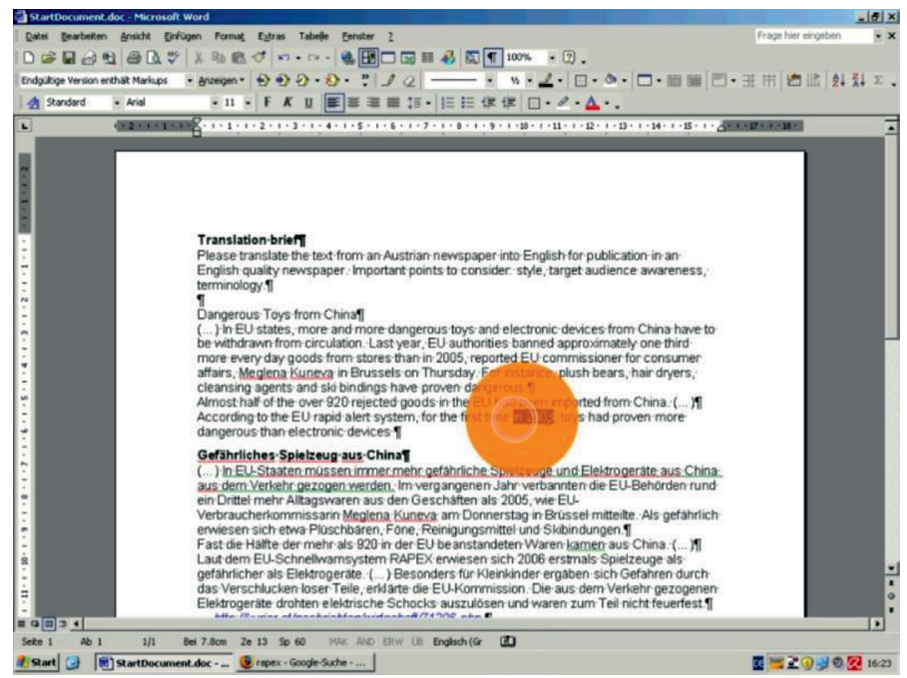

Figure 3. Sample fixation of time adverbials in ET0413's eye-tracking record 
its translation, and then continually shifted her focus of attention between the 5 th sentence of the ST and her emerging TT. She reread her TT sentence several times, fixating especially on the two time adverbials in it (see Figure 3). Finally, she reread the 5 th sentence of the ST two more times before moving on to the 6 th sentence.

\subsection{Third level of progression analysis: awareness of decision-making}

The methods discussed above allow inferences to be made about the problems that the translator encountered and how she dealt with them but not about whether she was aware of what she was doing. When the translator viewed the screen recording of her process, she indicated in her retrospective verbalization that she was aware of the difficulty she had had with the time adverbials and attributed it to the fact that she was translating into her L2 (Table 2).

Table 2. Extracts from ET0413's RVP related to the production of the 5th sentence

\begin{tabular}{ll} 
Time & Comment \\
\hline $00: 11: 59$ & $\begin{array}{l}\text { here comes the part I actually thought about the most... which information should come where in the } \\
\text { English sentence. At the end I still wasn't really convinced of my solution and I changed it around at the } \\
\text { end. }\end{array}$ \\
$00: 12: 26 \quad \begin{array}{l}\text { ok, that is the first variant, then another one, a second and a third...I find it difficult to place all these } \\
\text { adverbials in English ... putting it at the beginning of the sentence might work with one but with two it } \\
\text { gets harder } \\
\text { and now I fiddled around with it again...yeah, I somehow have the feeling that a native speaker could say } \\
\text { this better... it probably wouldn't be a problem for them... putting things in the right order. This is } \\
\text { exactly the handicap I have as a non-native speaker. }\end{array}$ &
\end{tabular}

The information from the cue-based RVP substantiates that the problem identified with the other methods was indeed a problem for the translator, that she seemed to understand what type of problem it was, and that she had constructed an explanation for the source of the problem (cf. Muñoz Martín 2010,181). This explanation was tested with version analysis of other TTs from the corpus that hers was drawn from, as described below.

\subsection{Version analysis of translation products}

In our longitudinal study, various groups of translators have translated the same source texts under similar conditions, which makes a direct comparison of translation products possible with version analysis. The translation processes of the five volunteers and five randomly chosen processes recorded from their peers two years before were compared to those of nine freelance professionals who had translated the ST into their L1. In particular, the translation of the adjacent time adverbials in the 5th sentence of the ST was examined in detail (marked in bold and italics, respectively, in Table 3). Although no two versions were identical, most 
Table 3. Version analysis of translations by students (into L2) and professionals (into L1) Translations of "erwiesen sich $\mathbf{2 0 0 6}$ erstmals Spielzeuge als gefährlicher als Elektrogeräte." $\quad$ Translator in 2006, toys proved for the first time to be more dangerous than electric appliances. $\quad$ UE0315 in 2006, toys were for the first time more dangerous than electrical appliances. $\quad$ UE0321 in $\mathbf{2 0 0 6}$ toys proved to be more harmful than electronic devices for the first time. $\quad$ ET0402

In 2006, [...] proved toys to be more dangerous than electronic devices for the first time. UE0317

toys were in $\mathbf{2 0 0 6}$ more dangerous than electrical appliances for the first time. ET0314

. toys had proven more dangerous than electronic devices for the first time in 2006. toys proved to be more dangerous than electrical appliances for the first time in $\mathbf{2 0 0 6} . \quad$ ET0405 certain toys have emerged to be more dangerous than electronical devices for the first time in 2006. UE0311 toys were considered to be more dangerous than electronic devices for the first time in 2006. ET0411 $\mathbf{2 0 0 6}$ has been the first year in which toys proved to be more dangerous than electric appliances. UE0310 in 2005 [sic], toys for the first time overtook electrical appliances as the most dangerous products. $\quad$ Pro0707 toys were found to be more dangerous than electrical equipment in $\mathbf{2 0 0 6}$ for the first time. $\quad$ Pro0714 toys were found to be more dangerous than electronic equipment fort he [sic] first time in $2006 . \quad$ Pro0704

$\exists \quad$ toys turned out to be more dangerous than electrical appliances for the first time in $\mathbf{2 0 0 6}$.

toys showed themselves to be more dangerous than electrical goods for the first time in 2006. toys were first identified as being more dangerous than electric appliances in $\mathbf{2 0 0 6}$.

2006 was the first year in which toys were found to be more dangerous than electrical goods. $\mathbf{2 0 0 6}$ was the first year that toys proved to be more dangerous than electrical appliances. 2006 saw toys being branded as more dangerous than electrical equipment for the first time.

of the L2 translators either maintained the ST order of the two time adverbials but separated them with other sentence constituents or kept them adjacent but reversed the order and put them at the end of the sentence. Only one of them expressed the time information in sentence constituents other than adverbials (i.e., UE0310), a convincing solution except for the verb form.

The solutions by the professionals were not very different from those of the students: all of the patterns in the L2 translations also appeared in the L1 translations. However, there was more variety in the relative positions of the time adverbials in the L1 translations and more of a tendency to put the time information into other sentence constituents. This could reflect greater confidence on the part of the professionals in exploiting the linguistic resources of their L1 but it could also be due to their experience.

The participant whose process was examined in the previous section (ET0413) shared her solution to the time adverbials with three other students and three professionals. Interestingly, the variety of patterns in the version analysis of the two groups is very similar to the variety of versions of the sentence as ET0413 struggled with the positions of the time adverbials in her target text (Appendix B). Her solutions otherwise all matched the ST structure, whereas some of the other translators seemed more prepared to depart from the ST and to convey the information in different forms. In fact, the only student who did exactly that seemed to have little difficulty with this sentence (i.e., no revisions and no mention of it in the cue-based RVP). Other cue-based RVPs suggest that this could be a good strategy, as one of the professionals commented: "when a German sentence is turned the wrong way, and you don't know what else to do, I always use the verb to see" (Pro0709). 


\section{Transferring research findings to training and back to the workplace}

Just as with newswriting processes, the different levels of progression analysis reveal information about reading processes, revision, research, consultation, and problem-solving during the process of translation. Combining data from the three levels can help us identify when self-concepts associated with psychobiography, such as those concerning world knowledge or target language competence, may be putting undue strain on translators' cognitive resources. If a translation problem can be attributed to a lack of target-language competence, then a good strategy might be to exploit other linguistic or contextual resources, such as relying on other-revision in a text production chain rather than simply increasing the amount of self-revision (cf. Mossop 2007).

Progression analysis allows a more detailed examination of translation problems than most product analyses do, since each action performed on the computer can be reconstructed for every process or partial process. Version analyses can be used to determine how a particular translator or groups of translators deal with similar types of problems. With groups translating a single source text, various translations can be compared; in the workplace setting, when a ST is usually only translated once into each language, translations of STs with similar syntactic structures, terminology, genre conventions, and rhetorical purposes can be compared. Progression analysis can be applied in both settings and thus is suitable for use in experiments as well as in ethnographic investigations of communities of practice.

The insights gained from progression analysis about translation practices and translators' decision-making are being transferred into evidence-based translation training and coaching. In line with the results from transdisciplinary action research in related fields (cf. Bremner 2012; Jones and Stubbe 2004; Krohn 2008), we have found that students and professionals seem to profit from seeing not only what they and others do but also how they do it. The next step will be to apply the results of progression analysis towards optimizing work processes and conditions at the translation workplace.

\section{Notes}

1. See www.linguistik.zhaw.ch/iued/capturing for further information about the Capturing Translation Processes project.

2. Financial support from the Swiss National Science Foundation for this project is gratefully acknowledged (Grant 13DFD3_124653/1).

3. See Ehrensberger-Dow and Künzli (2010) for further details. 
4. See Massey and Ehrensberger (2010) for a discussion of search behavior related to this sentence.

\section{References}

Archer, Margaret. 2003. Structure, Agency and the Internal Conversation. Cambridge: Cambridge University Press.

Bremner, Stephen. 2012. "Socialization and the Acquisition of Professional Discourse." Written Communication 29 (1): 7-32.

Ehrensberger-Dow, Maureen, and Alexander Künzli. 2010. "Methods of Accessing Metalinguistic Awareness: A Question of Quality?” In New Approaches in Translation Process Research, ed. by Susanne Göpferich, Fabio Alves, and Inger Mees, 113-132. Copenhagen: Samfundslitteratur. [Copenhagen Studies in Language, 39.]

Englund Dimitrova, Birgitta. 2005. Expertise and Explicitation in the Translation Process. Amsterdam: John Benjamins.

Hansen, Gyde. 2006. "Retrospection Methods in Translator Training and Translation Research." Journal of Specialised Translation 5: 2-41.

Jääskeläinen, Riitta. 2011. "Back to Basics: Designing a Study to Determine the Validity and the Reliability of Verbal Report Data on Translation Processes.” In Cognitive Explorations of Translation, ed. by Sharon O'Brien, 15-29. London: Continuum.

Jacobs, Geert. 2011. "Press Conferences on the Internet." Journal of Pragmatics 43 (7): 1900-1911. Jakobsen, Arnt L. 2006. "Research Methods in Translation - Translog." In Computer Key-Stroke Logging and Writing: Methods and Applications, ed. by Kirk P. H. Sullivan and Eva Lindgren, 95-105. Oxford: Elsevier.

Jones, Deborah, and Maria Stubbe. 2004. "Communication and the Reflective Practitioner. A Shared Perspective from Sociolinguistics and Organisational Communication." International Journal of Applied Linguistics 14 (2): 185-211.

Juzwik, Mary M., Svjetlana Curcic, Kimberly Wolbers, Kathleen D. Moxley, Lisa M. Dimling, and Rebecca K. Shankland. 2006. "Writing into the 21st Century: An Overview of Research on Writing, 1999 to 2004." Written Communication 23 (4): 451-476.

Kollberg, Py. 1998. S-Notation - A Computer-Based Method for Studying and Representing Text Composition. Licentiate thesis, Royal Institute of Technology, IPLab, Stockholm.

Kollberg, Py, and Kerstin Severinson Eklundh. 2001. "Analyzing Writers' Revising Patterns with S-Notation Analysis." In Contemporary Tools and Techniques for Studying Writing, ed. by Thierry Olive and C. Michael Levy, 89-104. Dordrecht: Kluwer Academic Publishers.

Krohn, Wolfgang. 2008. "Learning from Case Studies." In Handbook of Transdisciplinary Research, ed. by Holger Hoffmann-Riem et al., 369-383. Berlin: Springer.

Lee-Jahnke, Hannelore. 2005. "New Cognitive Approaches in Process-Oriented Translation Training." Meta 50 (2): 359-377.

Levy, C. Michael, J. Pamela Marek, and Joseph Lea. 1996. "Concurrent and Retrospective Protocols in Writing Research." In Theories, Models and Methodology in Writing Research, ed. by Gert Rijlaarsdam, Huub Van den Bergh, and Michael Couzijn, 542-556. Amsterdam: Amsterdam University Press.

Massey, Gary, and Maureen Ehrensberger-Dow. 2010. "Investigating Demands on Language professionals." Bulletin suisse de linguistique appliquée (Special Issue 1): 127-141. 
Mossop, Brian. 2007. "Empirical Studies of Revision: What We Know and Need to Know." The Journal of Specialised Translation 8: 5-20.

Muñoz Martín, Ricardo. 2010. “On Paradigms and Cognitive Translatology." In Translation and Cognition, ed. by Gregory Shreve and Erik Angelone, 169-187. Amsterdam: John Benjamins.

Perrin, Daniel. 2003. "Progression Analysis (PA). Investigating Writing Strategies at the Workplace." Journal of Pragmatics 35 (6): 907-921.

Perrin, Daniel. 2006. "Progression Analysis: An Ethnographic, Computer-Based Multi-Method Approach to Investigate Natural Writing Processes." In Writing and Digital Media, ed. by Luuk Van Waes, Mariëlle Leijten, and Christine M. Neuwirth, 173-179. Oxford: Elsevier.

Perrin, Daniel. In press. The Linguistics of Newswriting. Amsterdam: John Benjamins.

Perrin, Daniel, and Maureen Ehrensberger-Dow. 2008. "Media Competence." In Handbook of Communicative Competence, ed. by Gert Rickheit and Hans Strohner, 277-312. New York: de Gruyter.

Rijlaarsdam, Gert, Huub Van den Bergh, and Michael Couzijn (eds). 1996. Theories, Models and Methodology in Writing Research. Amsterdam: Amsterdam University Press.

Tashakkori, Abbas, and Charles Teddlie. 2003. "Major Issues and Controversies in the Use of Mixed Methods in Social and Behavioral Research." In Handbook of Mixed Methods in Social and Behavioral Research, ed. by Abbas Tashakkori and Charles Teddlie, 3-50. Thousand Oaks: Sage.

Van Hout, Tom, Henk Pander Maat, and Wim De Preter. 2011. "Writing from News Sources. The Case of Apple TV." Journal of Pragmatics 43 (7): 1876-1889.

Van Waes, Luuk, and Mariëlle Leijten. 2006. "Logging Writing Processes with Inputlog." In Writing and Digital Media, ed. by Luuk Van Waes, Mariëlle Leijten, and Christine M. Neuwirth, 158-165. Oxford: Elsevier.

\section{Appendix A: Translation brief and German source text}

\section{Translation brief}

Please translate the text from an Austrian newspaper into English for publication in an English quality newspaper. Important points to consider: style, target audience awareness, terminology.

\section{Gefährliches Spielzeug aus China}

(...) In EU-Staaten müssen immer mehr gefährliche Spielzeuge und Elektrogeräte aus China aus dem Verkehr gezogen werden. Im vergangenen Jahr verbannten die EU-Behörden rund ein Drittel mehr Alltagswaren aus den Geschäften als 2005, wie EU-Verbraucherkommissarin Meglena Kuneva am Donnerstag in Brüssel mitteilte. Als gefährlich erwiesen sich etwa Plüschbären, Föne, Reinigungsmittel und Skibindungen.

Fast die Hälfte der mehr als 920 in der EU beanstandeten Waren kamen aus China. (...)

Laut dem EU-Schnellwarnsystem RAPEX erwiesen sich 2006 erstmals Spielzeuge als gefährlicher als Elektrogeräte. (...) Besonders für Kleinkinder ergäben sich Gefahren durch das Verschlucken loser Teile, erklärte die EU-Kommission. Die aus dem Verkehr gezogenen Elektrogeräte drohten elektrische Schocks auszulösen und waren zum Teil nicht feuerfest.

$\rightarrow$ http://kurier.at/nachrichten/wirtschaft/71206.php 


\section{Appendix B: Steps in ET0413's production of the 5th sentence of the target text}

\begin{tabular}{|c|c|c|}
\hline Start time & Action & Sentence version \\
\hline $00: 11: 21$ & writes & According to the rapid alers \\
\hline $00: 11: 45$ & backspaces & According to the rapid alers \\
\hline $00: 11: 45$ & writes & According to the rapid alert si \\
\hline $00: 11: 46$ & backspaces & According to the rapid alert si \\
\hline $00: 11: 46$ & writes & According to the rapid alert system \\
\hline $00: 11: 53$ & $\underline{\text { inserts }}$ & According to the EU rapid alert system \\
\hline $00: 11: 58$ & $\overline{\text { writes }}$ & According to the $\overline{\mathrm{EU}}$ rapid alert system, 2006 \\
\hline 00:12:06 & backspaces & According to the EU rapid alert system, 2006 \\
\hline $00: 12: 12$ & writes & According to the EU rapid alert system, in 2006 , toys hav \\
\hline $00: 12: 20$ & backspaces & According to the EU rapid alert system, in 2006 , toys ha \\
\hline $00: 12: 21$ & writes & $\begin{array}{l}\text { According to the EU rapid alert system, in } 2006 \text {, toys had proven more dangerous } \\
\text { than electronic devices }\end{array}$ \\
\hline $00: 12: 37$ & $\underline{\text { inserts }}$ & $\begin{array}{l}\text { According to the EU rapid alert system, for the first time in 2006, toys had proven } \\
\text { more dangerous than electronic devices }\end{array}$ \\
\hline $00: 12: 54$ & ents & $\begin{array}{l}\text { According to the EU rapid alert system, for the first time } 2006 \text {, toys had proven } \\
\text { more dangerous than electronic devices }\end{array}$ \\
\hline $00: 12: 55$ & pastes & $\begin{array}{l}\text { According to the EU rapid alert system, for the first time, toys had proven more } \\
\text { dangerous than electronic devices in } 2006\end{array}$ \\
\hline $00: 13: 12$ & writes & $\begin{array}{l}\text { According to the EU rapid alert system, for the first time, toys had proven more } \\
\text { dangerous than electronic devices in } 2006 \text {. }\end{array}$ \\
\hline $00: 13: 14$ & euts & $\begin{array}{l}\text { According to the EU rapid alert system, for the first time, toys had proven more } \\
\text { dangerous than electronic devices in } 2006 \text {. }\end{array}$ \\
\hline $00: 13: 15$ & pastes & $\begin{array}{l}\text { According to the EU rapid alert system, for the first time in } 2006 \text {, toys had proven } \\
\text { more dangerous than electronic devices. }\end{array}$ \\
\hline $00: 13: 20$ & deletes & $\begin{array}{l}\text { According to the EU rapid alert system, for the first time in } 2006 \text {, toys had proven } \\
\text { more dangerous than electronic devices. }\end{array}$ \\
\hline $00: 13: 22$ & inserts & $\begin{array}{l}\text { According to the EU rapid alert system, in } 2006 \text { for the first time, toys had proven } \\
\text { more dangerous than electronic devices. }\end{array}$ \\
\hline $00: 13: 23$ & euts & $\begin{array}{l}\text { According to the EU rapid alert system, in } 2006 \text { for the first time, toys had proven } \\
\text { more dangerous than electronic devices. }\end{array}$ \\
\hline $00: 13: 27$ & pastes & $\begin{array}{l}\text { According to the EU rapid alert system, in } 2006 \text {, toys had proven more dangerous } \\
\text { than electronic devices for the first time. }\end{array}$ \\
\hline & .. & $\ldots$ (continues translating rest of source text) \\
\hline $00: 18: 42$ & $\underline{\text { inserts }}$ & $\begin{array}{l}\text { According to the EU rapid alert system RAPEX, in } 2006 \text {, toys had proven more } \\
\text { dangerous than electronic devices for the first time. }\end{array}$ \\
\hline $00: 18: 48$ & euts & $\begin{array}{l}\text { According to the EU rapid alert system RAPEX, in } 2006 \text {, toys had proven more } \\
\text { dangerous than electronic devices for the first time. }\end{array}$ \\
\hline $00: 18: 50$ & pastes & $\begin{array}{l}\text { According to the EU rapid alert system RAPEX, , toys had proven more dangerous } \\
\text { than electronic devices for the first time in } 2006 .\end{array}$ \\
\hline $00: 18: 54$ & deletes & $\begin{array}{l}\text { According to the EU rapid alert system RAPEX, }- \text {, toys had proven more dangerous } \\
\text { than electronic devices for the first time in } 2006 \text {. }\end{array}$ \\
\hline
\end{tabular}

\section{Authors' addresses}

Corresponding author:

Maureen Ehrensberger-Dow

Institute of Translation and Interpreting

Zurich University of Applied Sciences

Theaterstrasse 15c

CH-8401 WINTERTHUR

Switzerland

ehre@zhaw.ch
Daniel Perrin

Institute of Applied Media Studies

Zurich University of Applied Sciences

Theaterstrasse $15 \mathrm{c}$

CH-8401 WINTERTHUR

Switzerland

pdan@zhaw.ch 